\title{
Spiritual Well-Being and Depression in Patients with Heart Failure
}

\author{
David B. Bekelman, $M D^{7}$, Sydney M. Dy, MD'2, Diane M. Becker, $S c D^{3}$, Ilan S. Wittstein, $M D^{4}$, \\ Danetta E. Hendricks, MA'2, Traci E. Yamashita, $M S^{7}$, and Sheldon H. Gottlieb, MD ${ }^{5}$
}

'Department of Medicine, Division of General Internal Medicine University of Colorado at Denver and Health Sciences Center, 4200 East Ninth Avenue, B180, Denver, CO 80262, USA; ${ }^{2}$ Department of Health Policy \& Management, Bloomberg School of Public Health Johns Hopkins University, Baltimore, MD, USA; ${ }^{3}$ Division of Internal Medicine The Johns Hopkins University School of Medicine, Baltimore, MD, USA; ${ }^{4} \mathrm{Johns}$ Hopkins Hospital, Baltimore, MD, USA; ${ }^{5}$ Johns Hopkins Bayview Medical Center, Baltimore, MD, USA.

BACKGROUND: In patients with chronic heart failure, depression is common and associated with poor quality of life, more frequent hospitalizations, and higher mortality. Spiritual well-being is an important, modifiable coping resource in patients with terminal cancer and is associated with less depression, but little is known about the role of spiritual well-being in patients with heart failure.

OBJECTIVE: To identify the relationship between spiritual well-being and depression in patients with heart failure.

DESIGN: Cross-sectional study.

PARTICIPANTS: Sixty patients aged 60 years or older with New York Heart Association class II-IV heart failure.

MEASUREMENTS: Spiritual well-being was measured using the total scale and 2 subscales (meaning/peace, faith) of the Functional Assessment of Chronic Illness Therapy-Spiritual Well-being scale, depression using the Geriatric Depression Scale-Short Form (GDS-SF).

RESULTS: The median age of participants was 75 years. Nineteen participants (32\%) had clinically significant depression (GDS-SF $>4$ ). Greater spiritual well-being was strongly inversely correlated with depression (Spearman's correlation -0.55, 95\% confidence interval -0.70 to -0.35$)$. In particular, greater meaning/peace was strongly associated with less depression $(r=-.60$, $P<.0001)$, while faith was only modestly associated

The study was funded by the Johns Hopkins Center for Complementary and Alternative Medicine; Johns Hopkins General Clinical Research Center; and the National Center for Complimentary and Alternative Medicine, NIH. None of these funders had a role in study design, data collection, analyses, interpretation, report writing, or decision to submit paper for publication.

This study was presented at the 52nd Annual Meeting of the Academy of Psychosomatic Medicine, November 17, 2005, Santa Ana Pueblo, NM; The Annual Assembly of the American Academy of Hospice and Palliative Medicine \& Hospice and Palliative Nurses Association, February 9, 2006, Nashville, TN; the 29th Society of General Internal Medicine Annual Meeting, April 26-29, 2006, Los Angeles, CA; and the 7th Scientific Forum on Quality of Care and Outcomes Research in Cardiovascular Disease and Stroke, May 7-9, 2006, Washington, DC.

Received June 16, 2006

Accepted October 20, 2006

Published online February 6, 2007 $(r=-.38, P<.01)$. In a regression analysis accounting for gender, income, and other risk factors for depression (social support, physical symptoms, and health status), greater spiritual well-being continued to be significantly associated with less depression $(P=.05)$. Between the 2 spiritual well-being subscales, only meaning/peace contributed significantly to this effect $(P=.02)$ and accounted for $7 \%$ of the variance in depression.

CONCLUSIONS: Among outpatients with heart failure, greater spiritual well-being, particularly meaning/ peace, was strongly associated with less depression. Enhancement of patients' sense of spiritual well-being might reduce or prevent depression and thus improve quality of life and other outcomes in this population.

KEY WORDS: heart failure; spirituality; depression; palliative care.

DOI: $10.1007 / \mathrm{s} 11606-006-0044-9$

(C) 2007 Society of General Internal Medicine 2007;22:470-477

\section{INTRODUCTION}

Depression is common in patients with chronic heart failure. Between $13.9 \%$ and $36.5 \%$ of heart failure patients have a depressive disorder, and even more have clinically significant depressive symptoms. ${ }^{1-3}$ In longitudinal studies of patients with heart failure, depression is associated with poor quality of life, ${ }^{4}$ short-term declines in health status, ${ }^{5}$ poor physical and social function, ${ }^{2,3}$ more frequent hospitalizations, and higher mortality. ${ }^{2,6}$ Depression is also associated with significantly increased costs in heart failure care and increased medical morbidity. ${ }^{3,7}$

Spiritual well-being is associated with less depression in patients with terminal cancer, but this relationship has not been studied in patients with heart failure. ${ }^{8,9}$ Heart failure as a chronic illness differs from cancer in that heart failure has a more unpredictable course with long-term loss of function and frequent waxing and waning of symptoms. ${ }^{10}$ Spirituality may play a major role in functioning, health status, and quality of life in heart failure patients because spiritual concerns are important to them and are significant in how they view and cope with their illness. ${ }^{11,12}$ One study examined longitudinal predictors of depression in patients with heart failure but did not consider the possible role of spiritual well-being on depression. ${ }^{13}$

Spirituality is often equated with religious faith; however, a broader and more inclusive definition is "the way in which people understand their lives in view of their ultimate meaning 
and value." ${ }^{14}$ Spiritual well-being refers to one's spiritual "state of affairs." 15 This conceptualization of spirituality is emphasized in palliative care, which has been advocated in patients with heart failure to relieve suffering and distress. ${ }^{16,17}$ However, we are not aware of any evidence demonstrating a relationship between spiritual well-being and other health outcomes in patients with heart failure.

The primary objective of this study was to identify the relationship between spiritual well-being and depression in an elderly heart failure population in the context of other common risk factors for depression, including low social support, poor health status, and number of physical symptoms. We hypothesized that greater spiritual well-being would be associated with less depression and that this relationship would persist after accounting for these other risk factors.

\section{PARTICIPANTS AND METHODS}

\section{Study Population}

We conducted a cross-sectional study in outpatients with heart failure between August 2004 and April 2005. Participants were recruited from cardiology clinics at an academic-affiliated community hospital and a tertiary care academic referral hospital in Baltimore, MD. Eligible study participants (1) had a cardiologist's diagnosis of heart failure; (2) had New York Heart Association (NYHA) functional class II, III, or IV according to a cardiologist; and (3) were age 60 years or older. Patients were excluded if they (1) were diagnosed with dementia, (2) were unable to understand the study protocol and provide informed consent, or (3) were listed on a heart transplant registry, because it has been shown that these patients have different psychosocial backgrounds and needs compared with those ineligible for heart transplant. ${ }^{18}$ After eligible patients gave informed consent, they completed the study instruments with the assistance of the primary investigator or study coordinator. The study was approved by the Institutional Review Board at the Johns Hopkins Bloomberg School of Public Health.

\section{Measurements}

Depression, the primary outcome, was measured using the Geriatric Depression Scale-Short Form (GDS-SF), a selfreport, reliable, and valid screening tool for current depression in this population. ${ }^{19,20}$ The GDS is widely used in elderly, medically ill populations because it excludes somatic symptoms of depression while maintaining sensitivity. ${ }^{21}$ The scale range is from 0 to 15 , with a higher score indicating a greater number of depressive symptoms. A score of 5 or higher is $60 \%$ sensitive and $89 \%$ specific for a diagnosis of depressive disorder. ${ }^{22}$ The scale has high internal consistency (Cronbach's alpha 0.80). ${ }^{22}$

Spiritual well-being, the primary predictor, was measured using the Functional Assessment of Chronic Illness TherapySpiritual Well-Being (FACIT-Sp) scale, a 12-item self-report measure that was developed and validated in a large sample of medically ill patients. ${ }^{8,23}$ The FACIT-Sp measures overall spiritual well-being (scale range, 0-48; higher scores signifying greater spiritual well-being). It includes 2 subscales: meaning/ peace and faith. The meaning/peace subscale measures a sense of meaning, peace and harmony, and purpose in life (scale range, 0-32). For example, one item reads "I know that whatever happens with my illness, things will be ok." The faith subscale assesses the relation between illness, faith, and spiritual beliefs, and how one finds solace in one's faith (scale range, $0-16) .{ }^{23}$ For example, "I find strength in my faith or spiritual beliefs." All 3 scales have high internal consistency (Cronbach's alpha for total scale, 0.87; for meaning/peace subscale, 0.81; for faith subscale, 0.88). ${ }^{23}$

Other known risk factors for depression were included as secondary predictor variables. These variables were identified based on a recent prospective, longitudinal study of independent predictors of depression incidence in outpatients with heart failure. ${ }^{13}$ Based on this prior work, we measured health status, social support, physical symptoms, alcohol and drug abuse, and sociodemographic variables as secondary predictor variables for depression. A conceptual framework of depression in people with heart failure is available for interested readers. ${ }^{24}$

Health status was assessed using the Kansas City Cardiomyopathy Questionnaire (KCCQ). The KCCQ is a valid, reliable, and responsive measure developed for patients with heart failure. ${ }^{25,26}$ The overall score (range, 0-100) strongly predicts future cardiovascular mortality and rehospitalization; a score of $\geq 75$ is associated with a $7 \%$ 1-year risk of hospitalization and $5 \%$ risk of death versus $37 \%$ and $20 \%$,

Table 1. Study Population Characteristics, $N=60$

\begin{tabular}{|c|c|}
\hline Characteristic & $n(\%)^{*}$ \\
\hline Female & $22(36.7)$ \\
\hline Age, years, median [IQR] & $75[70,81]$ \\
\hline Non-white & $7(11.7)$ \\
\hline Married/significant other or partner, $N=59$ & $30(50.8)$ \\
\hline \multicolumn{2}{|l|}{ Highest grade completed in school, $N=59$} \\
\hline Less than high school graduate & $25(42.4)$ \\
\hline High school graduate & $20(33.9)$ \\
\hline Additional education & $14(23.7)$ \\
\hline \multicolumn{2}{|l|}{ Total household income, $N=56$} \\
\hline Less than or equal to $\$ 20,000$ & $20(35.7)$ \\
\hline$\$ 20,001-\$ 30,000$ & 19 (33.9) \\
\hline More than $\$ 30,000$ & $17(30.4)$ \\
\hline \multicolumn{2}{|l|}{ Comorbid medical illness } \\
\hline Chronic obstructive pulmonary disease, $N=57$ & $10(17.5)$ \\
\hline Cancer, $N=55$ & $7(12.7)$ \\
\hline Stroke, $N=59$ & $11(18.6)$ \\
\hline Alcohol or drug abuse & $7(11.7)$ \\
\hline NT-proBNP pg/mL, $N=44$, median [IQR] & $2,547[651,8,610]$ \\
\hline MMSE score, median [IQR] & $29[28,29]$ \\
\hline $\begin{array}{l}\text { Spiritual well-being, total score (FACIT-Sp), } \\
\text { median [IGR] }\end{array}$ & $37[30,44]$ \\
\hline Social support score (ESSI-5 item), median [IQR] & $23[19,25]$ \\
\hline Health status score (KCCQ), median [IGR] & $71[48,90]$ \\
\hline $\begin{array}{l}\text { Number of physical symptoms (from MSAS-SF), } \\
\text { median [IQR] }\end{array}$ & $3[2,6]$ \\
\hline Depression score (GDS-SF), median [IQR] & $2[1,5]$ \\
\hline Clinically significant depression (GDS-SF>4) & $19(31.7)$ \\
\hline
\end{tabular}

$I Q R$ interquartile range, NT-proBNP N-terminal pro-brain natriuretic peptide, MMSE Mini-Mental State Examination, FACIT-Sp Functional Assessment of Chronic Illness Therapy-Spiritual Well-Being, ESSI Enhancing Recovery in Coronary Heart Disease Patients Social Support Inventory, KCCQ Kansas City Cardiomyopathy Questionnaire; MSAS-SF Memorial Symptom Assessment Scale-Short Form, GDS-SF Geriatric Depression Scale-Short Form.

*Unless otherwise noted 
Correlation*

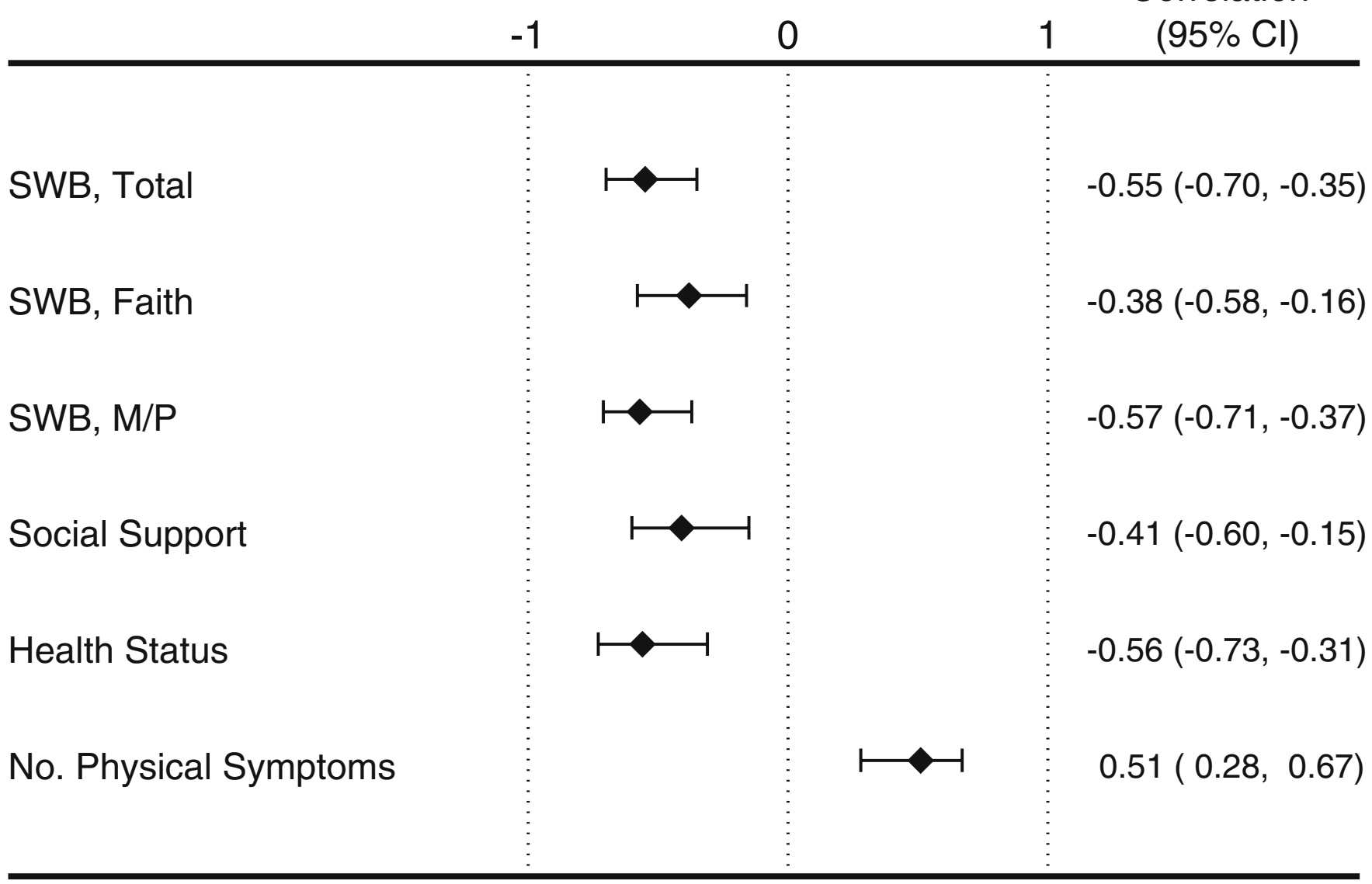

* Spearman correlation coefficient

Figure 1. Spearman correlation coefficients with $95 \%$ confidence intervals between the candidate predictors and depression. SWB spiritual well-being, $M / P$ meaning/peace.

respectively, for a score of $<25 .{ }^{27}$ Cronbach's alpha ranges from 0.78 to 0.90 for the subscales making up the overall score. The Enhancing Recovery in Coronary Heart Disease Patients (ENRICHD) Social Support Inventory (ESSI) measures structural, instrumental, and emotional aspects of social support and was developed using social support items previously found to be predictive of mortality in cardiovascular patients. ${ }^{28}$ It was created for and used in the ENRICHD study, the largest randomized controlled trial of psychotherapy for postmyocardial infarction depression to date. ${ }^{29}$ The scale range is 5-25 and higher scores reflect more social support. The scale has high internal consistency (Cronbach's alpha 0.86). The Memorial Symptom Assessment Scale-Short Form (MSAS-SF), used to assess the number of physical symptoms, detects self-reported presence or absence of 28 physical symptoms (scale range, 0-28). ${ }^{30}$ Initially validated and tested for reliability in cancer patients, the MSAS-SF has also been validated in heart failure patients. ${ }^{31}$

Alcohol and drug abuse were measured using a 2-item screen. ${ }^{32}$ For descriptive purposes, the standardized MiniMental State Exam was administered to evaluate cognitive status. ${ }^{33}$ Participants provided sociodemographic information along with history of other medical problems. N-terminal probrain natriuretic peptide (NT-proBNP) was measured to more fully characterize the level of left-ventricular dysfunction. It was determined using the Elecsys NT-proBNP sandwich electrochemiluminescence immunoassay on an Elecsys 2010 (Roche, Indianapolis, IN, USA) in the Johns Hopkins Clinical Chemistry Reference Laboratory.

There were no missing data for the MSAS-SF, KCCQ, and ESSI surveys. Four of the 60 participants (7\%) had incomplete GDS data, missing an average of 1.25 out of 15 items per person. For the missing items, we used a weighted GDS score as described on the instrument's web site, which removes the missing items from the denominator to avoid underestimation of the scale score. ${ }^{34}$ Only 1 participant had missing FACIT data, missing 4 items out of 12 . Because $<50 \%$ of the items were missing in total and subscales, we replaced the missing item with the average of the nonmissing items in the corresponding scales/subscales.

\section{Statistical Analysis}

Because the distribution of the depression score was nonGaussian, Wilcoxon rank sum and Kruskal-Wallis tests were used to check for differences in depression according to age (dichotomized at median 75 years) and categories of gender, race, marital status, education, and income, as displayed in Table 1. Spearman correlation coefficients were used to examine the bivariate association between depression and the 


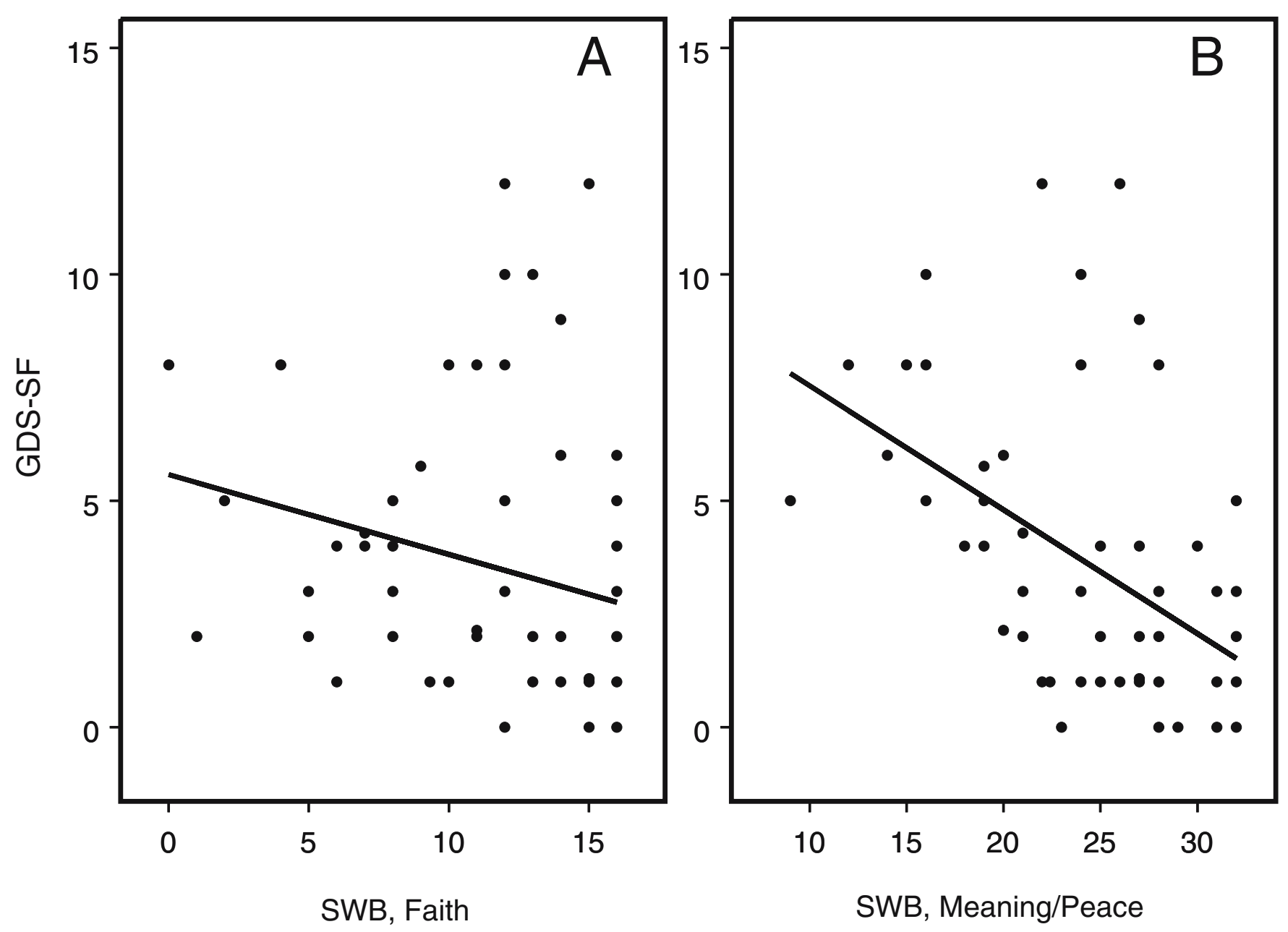

Figure 2. Scatter plot with fitted linear regression line showing the depression measure as a function of the faith (Panel $A$ ) and meaning/ peace (Panel B) subscales of the spiritual well-being measure. Spiritual well-being (SWB) faith scale range, 0-16; SWB meaning/peace scale range, 0-32; Geriatric Depression Scale-Short Form (GDS-SF) scale range 0-15.

primary and secondary predictors. Confidence intervals for correlations were estimated using a bias-corrected bootstrap technique (SAS JACKBOOT macro). Scatter plots with unadjusted linear regression lines were generated to show the relationship between depression and the 2 spiritual well-being subscales, faith and meaning/peace. To determine how spiritual well-being affected the depression score in the context of other risk factors, we stratified our study population into groups based on median scores of the predictor variables. Then, for each known risk factor and the spiritual well-being measure, we created 4 categories by combining low/high risk factor scores and low/high spiritual well-being scores. Histograms were created to compare the median levels of depression within each category; differences were tested with Wilcoxon rank sum tests.

Next, multivariate linear regression models were developed to test the hypotheses that the relationship between spiritual well-being and depression persisted after accounting for the other known depression risk factors (social support, number of physical symptoms, health status, and substance abuse). In addition, we were interested in determining which of the spiritual well-being measure subscales (faith or meaning/ peace) were most important in this relationship. We began with separate bivariate models for each of these secondary predictors and depression. Predictors which were associated with depression at $P \leq .15$ were then entered into an initial multivariate model adjusted by the demographic characteristics found to be associated with the depression score $(P \leq .15)$. Median depression scores differed according to the trichotomized income categories $(P=.12)$, and because these differences were driven by those with annual incomes $>\$ 30,000$ (median GDS $=1$ vs 4 for income below vs above $\$ 30,000$, $P=$.05), all adjustments for income used an income variable that was dichotomized at $\$ 30,000$. To determine whether the total spiritual well-being score and the 2 subscale scores continued to be associated with depression after adjusting for other potential confounders, as well as to determine how much of the variance in depression spiritual well-being accounted for, 3 additional models were generated. These 3 models included the variables in the initial model plus the total spiritual well-being score in the first model, the faith subscale score in the second model, and the meaning/peace subscale score in the third model. Analyses of residuals confirmed the appropriateness of these parametric models. Measures were analyzed as continuous variables. Statistical analyses were carried out using SAS version 9.1 (SAS Institute, Cary, NC, USA). 


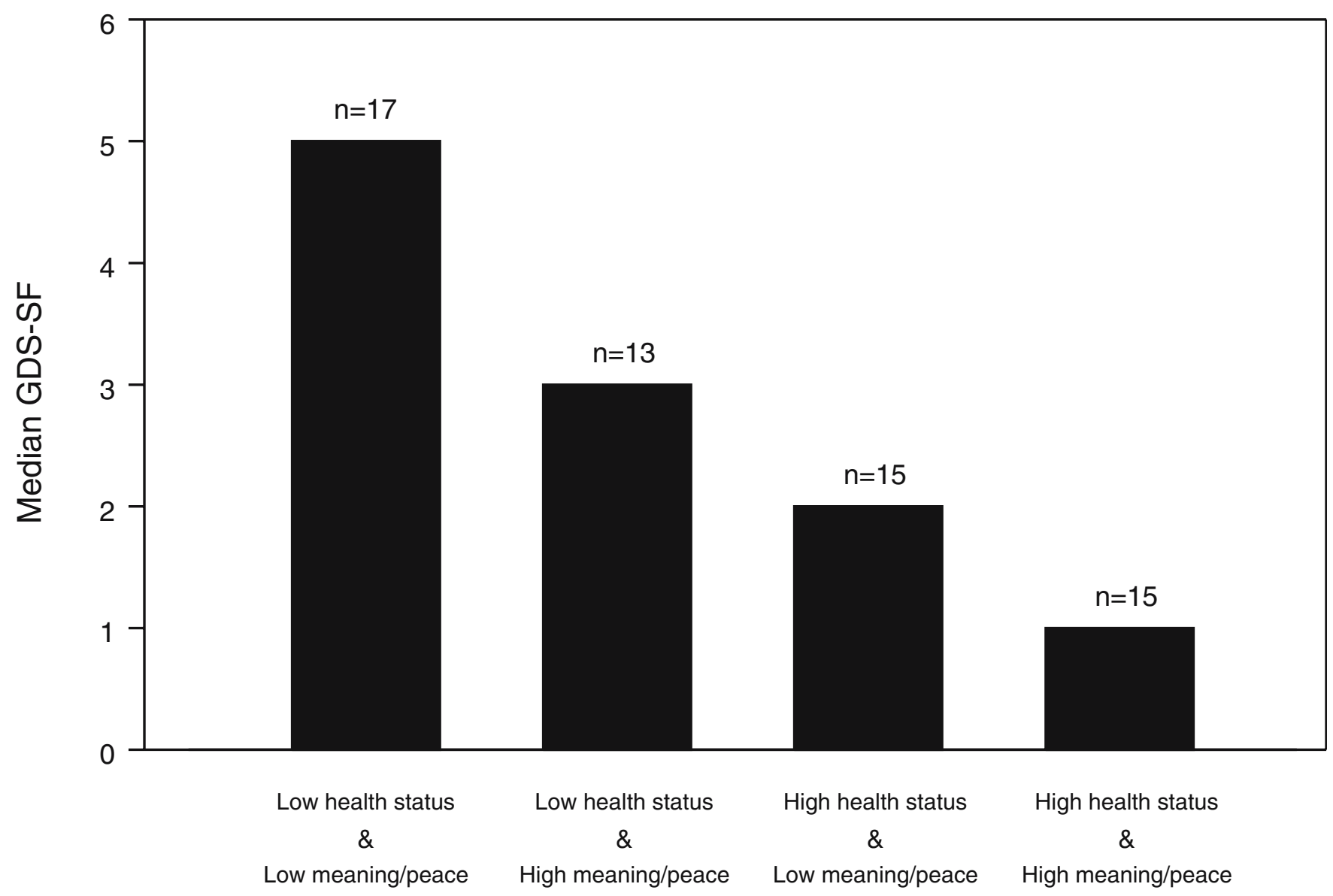

Figure 3. Histograms showing the relationship between spiritual well-being meaning/peace and health status on depressive symptoms. Health status was assessed with the Kansas City Cardiomyopathy Questionnaire (KCCQ) overall summary score and meaning/peace with the meaning/peace subscale of the Functional Assessment of Chronic Illness Therapy-Spiritual Well-Being scale. Participants were classified into either "low" or "high" health status if their KCCQ score was below or above the median score of the study population, respectively. Similarly, "low" or "high" meaning/peace denotes meaning/peace scores below or above the population median. GDS-SF, Geriatric Depression Scale-Short Form.

\section{RESULTS}

Of 111 patients approached, 63 were enrolled in the study. Three participants did not return surveys, yielding a final study population of 60 . The reasons for nonenrollment included lack of interest in participation $(N=28)$, being too ill $(N=4)$, lack of time for participation $(N=4)$, dying prior to study completion $(N=2)$, or other reasons $(N=10)$. Approximately $10 \%$ of patients completed the surveys at home and returned them by mail within 48 hours of the clinic visit. There were no significant differences at the 0.05 level in gender, race, or age between those enrolled and those who were not.

The study population is described in Table 1 . The median age of participants was 75 years. A minority were women (37\%) and non-white (12\%). Most had been educated through high school or beyond (58\%). Our study population's median household income category $(\$ 20,001$ to $\$ 30,000)$ includes the median U.S. population household income for persons aged 65 years and older $(\$ 26,036) .{ }^{35}$ Thirty-two percent had current clinically significant depression (GDS-SF $>4$ ). The median

Table 2. Results from Regression Models with Total Spiritual Well-Being, Faith, and Meaning/Peace Subscales, $N=56$

\begin{tabular}{|c|c|c|c|c|}
\hline Variable & Model 1 (95\% Cl) & Model 2 (95\% Cl) & Model $3(95 \% \mathrm{Cl})$ & Model $4(95 \% \mathrm{Cl})$ \\
\hline Gender & $0.65(-0.91,2.22)$ & $0.80(-0.72,2.32)$ & $0.79(-0.82,2.40)$ & $0.62(-0.87,2.11)$ \\
\hline Income & $1.09(-0.53,2.71)$ & $1.11(-0.46,2.68)$ & $1.16(-0.47,2.80)$ & $0.97(-0.57,2.51)$ \\
\hline Social support & $-0.12(-0.29,0.05)$ & $-0.08(-0.25,0.09)$ & $-0.10(-0.28,0.07)$ & $-0.08(-0.25,0.09)$ \\
\hline No. physical symptoms & $0.08(-0.07,0.24)$ & $0.05(-0.11,0.20)$ & $0.07(-0.09,0.23)$ & $0.04(-0.11,0.19)$ \\
\hline Health status & $-0.05(-0.09,-0.02)$ & $-0.05(-0.08,-0.01)$ & $-0.05(-0.09,-0.01)$ & $-0.05(-0.08,-0.02)$ \\
\hline Spiritual well-being, total & & $-0.09(-0.17,-0.00)$ & & \\
\hline Spiritual well-being, faith & & & $-0.07(-0.26,0.11)$ & \\
\hline Spiritual well-being, meaning/peace & & & & $-0.15(-0.27,-0.03)$ \\
\hline Model $R$-squared & 0.43 & 0.48 & 0.44 & 0.50 \\
\hline
\end{tabular}

CI confidence interval 
health status (KCCQ score) of 71 has been associated with NYHA class II. ${ }^{25}$ Women were more likely to have higher depression scores (median GDS for $m e n=2$, for women $=4$, $P=.04)$. Neither race, age, education, marital status, nor screening questions for substance abuse was associated with depression (data not shown).

Spearman correlation coefficients and 95\% confidence intervals between the predictors and depression are shown in Figure 1. Greater total spiritual well-being $\left(r_{\mathrm{s}}=-.55\right.$, $P<.001)$, social support $\left(r_{\mathrm{s}}=-.41, P<.01\right)$, health status $\left(r_{\mathrm{s}}=\right.$ $-.56, P<.001)$, and fewer physical symptoms $\left(r_{\mathrm{s}}=.41, P<.01\right)$ were significantly associated with less depression. In particular, greater meaning/peace was strongly associated with less depression $\left(r_{\mathrm{s}}=-.57, P<.001\right)$, while faith was less strongly associated $\left(r_{\mathrm{s}}=-.38, P<.01\right)$. These 2 relationships are depicted in Figure 2 in more detail. Greater meaning/peace was strongly associated with less depression $\left(P<.001 R^{2}=.25\right)$, while faith was less strongly associated $\left(P=.07, R^{2}=.05\right)$.

Figure 3 illustrates the relationship between spiritual wellbeing meaning/peace, health status, and depression. Regardless of health status level, meaning/peace had a significant effect on the median depression symptom score (for low health status, GDS-SF $=5$ vs 3, $P=.02$; for high health status, GDS-SF= 2 vs $1, P<.01$ for low vs high meaning/peace, respectively). Furthermore, among those with low health-status scores, spiritual well-being had a clinically meaningful effect on depression; those with low meaning/peace had a GDS-SF score of 5, indicative of clinically significant depressive symptoms, while the high-meaning/peace group's score of 3 suggested nonclinically significant depressive symptoms. Similar qualitative relationships were seen for both social support and number of physical symptoms (data not shown).

In the multivariate linear regression models (Table 2), the overall measure of spiritual well-being was independently associated with depression $(P=.05)$. However, between the 2 spiritual well-being subscales, only meaning/peace contributed significantly to this effect $(P=.02)$ and accounted for $7 \%$ of the variance in depression symptoms.

\section{DISCUSSION}

In a sample of outpatients with symptomatic heart failure, greater spiritual well-being was strongly associated with less depression. In unadjusted analyses, greater social support, fewer physical symptoms, better health status, gender, and income were also associated with less depression. Greater meaning/peace continued to be significantly associated with less depression when adjusted for these other predictors of depression.

Our study confirms and extends findings from other studies of depression in patients with heart failure. The $32 \%$ prevalence of clinically significant depression in our sample of heart failure outpatients is similar to the $30 \%$ prevalence found in a larger outpatient sample. ${ }^{5}$ We also confirmed associations between social support, health status, and depression found in another study. ${ }^{13}$ Few other studies have evaluated the importance of spiritual well-being in patients with heart failure. Both existential and religious aspects of spirituality were found to be significant contributors to quality of life in a group of patients with heart failure. ${ }^{36}$ A qualitative study found that outpatients with heart failure relied on spirituality to adjust to advancing heart failure. ${ }^{12}$ A longitudinal qualitative study of patients with heart failure and their caregivers showed that patients frequently expressed spiritual needs and distress and were interested in talking about them with health care professionals. ${ }^{37}$ Our research adds to these studies by finding a strong, quantitative relationship between greater meaning/peace (but not faith) and less depression.

One potential limitation to this study is the measurement of spiritual well-being. While some controversy still exists, a differentiation between the existential (i.e., meaning/peace) and religious aspects of spirituality is supported by qualitative and quantitative research. ${ }^{9,15,37,38}$ These studies and others show that patients readily identify attitudes, ways of coping, and aspects of distress that reflect spiritual well-being. A related concern is that psychological well-being and spiritual well-being are overlapping constructs. Both qualitative ${ }^{37}$ and quantitative $^{39}$ research suggest they are separate domains that are distinct components of overall quality of life. Longitudinal studies could help define causal relationships between spiritual well-being, psychological well-being, and other risk factors for depression. Another limitation in this study is the small sample size that limited our ability to explore additional relationships and interactions between psychosocial factors, spiritual well-being, and depression. An additional limitation is that we bundled the analysis of surveys that were completed with interviewer assistance with the small minority of participants (10\%) who completed surveys at home and mailed them in. Finally, even though the demographic characteristics of those who enrolled and did not enroll were similar, a selection bias in the enrollees may have occurred if people with greater depression elected not to enroll.

Why was greater meaning/peace but not faith strongly correlated with less depression? These aspects of spirituality may be more important to how people cope with chronic illness. Having a deep sense of meaning or purpose in life may impart a comfort that allows transcendence of the limitations and life changes associated with chronic illness. Similar results have been found in a study of terminally ill cancer patients. ${ }^{8}$ A recent study highlighted the importance of the construct of being "at peace" in medical decision making and in emotional and spiritual well-being in a group of patients with advanced chronic medical illness. ${ }^{40}$ Better characterization of spiritual coping could lead to effective patient-centered approaches to enhance this potentially protective resource.

There has been little work hypothesizing and testing possible mechanisms by which greater spiritual well-being leads to reduced depression and other beneficial health effects. This is an important area for future research. Several researchers have postulated that spiritual well-being may lead to less depression through enhanced psychological coping. ${ }^{8,41}$ Levin has described additional pathways by which religious involvement might influence health, and spirituality may be linked to health in similar ways. ${ }^{42}$ These pathways include the association of religious commitment with health-related behaviors (avoidance of smoking and drug use), heredity transmission, social support (enabling stress-buffering and adaptation), ritual (e.g., prayer or meditation engendering positive emotions), belief (association between spiritual worldviews and health beliefs and behaviors), faith (optimism and positive expectation leading to a "placebo effect"), the "superempirical" (force or energy believed in by faith traditions but not generally accepted by western biomedical science), and the supernatural (the work of God). 
Our results raise the question of whether enhancing patients' sense of meaning/peace might reduce or prevent depression and thus improve quality of life in patients with heart failure. Few spiritual interventions have been tested. The few that have been tested target people with advanced cancer. Meaning-centered group psychotherapy aims to help people with advanced cancer to sustain or enhance a sense of meaning, peace, and purpose in their lives even as they approach the end of life. ${ }^{43}$ It is based on Viktor Frankl's development of logotherapy, or meaning-based psychotherapy. Dignity therapy is another intervention that was developed through a qualitative study of 50 dying patients and their perceptions and concerns related to dignity. ${ }^{44}$ Dignity therapy addresses psychosocial and existential distress among terminally ill patients by asking them to discuss issues that matter most or that they would most want remembered. These interviews are transcribed and edited and a final document is generated that can be given to friends or family. An initial study demonstrated that this intervention enhanced dignity, sense of purpose, and meaning. ${ }^{44}$ In addition, postintervention measures of suffering and depressive symptoms were improved. Referrals to chaplains may also be helpful. Chochinov et al. recently reviewed additional approaches to spiritual care at the end of life. ${ }^{41}$

These spiritual interventions have not been evaluated in cardiac patients. In cardiac patients, the treatment of depression is associated with improved quality of life. The ENRICHD trial found that the treatment of depression with cognitivebehavioral psychotherapy and as-needed supplemental antidepressants led to improvements in several domains of quality of life in post-MI patients. ${ }^{45}$ How to best improve spiritual wellbeing in patients with heart failure or other chronic illnesses or whether this would lead to reduced depression or improved quality of life is unknown.

While targeting spiritual well-being may be beneficial, it is important to note that social support, physical symptoms, and health status were also related to depression in this study in bivariate analyses. Only health status was associated with depression in multivariate models, although type-II error may have been responsible for the lack of association between social support, physical symptoms, and depression in these models. Previous work has also found that risk factors for depression in patients with heart failure span the physical and psychosocial domains. ${ }^{13}$ One approach to address the multiple factors associated with depression and poor quality of life in heart failure patients may be the early incorporation of palliative care. ${ }^{16,17}$ Palliative care addresses spiritual wellbeing, as well as the other domains that were associated with depression in this study, and may be an underutilized resource in caring for patients with heart failure.

Acknowledgements: The authors wish to thank the seriously ill patients in the study for their participation.

\section{Potential Financial Conflicts of Interest: None disclosed}

Corresponding Author: David B. Bekelman, MD; Department of Medicine, Division of General Internal Medicine University of Colorado at Denver and Health Sciences Center, 4200 East Ninth Avenue, B180, Denver, CO 80262, USA (e-mail: David.Bekelman@UCHSC. edu).

\section{REFERENCES}

1. Freedland KE, Rich MW, Skala JA, Carney RM, Davila-Roman VG, Jaffe AS. Prevalence of depression in hospitalized patients with congestive heart failure. Psychosom Med. 2003;65:119-28.

2. Vaccarino V, Kasl SV, Abramson J, Krumholz HM. Depressive symptoms and risk of functional decline and death in patients with heart failure. J Am Coll Cardiol. 2001;38:199-205.

3. Koenig HG. Depression in hospitalized older patients with congestive heart failure. Gen Hosp Psychiatry. 1998;20:29-43.

4. Sullivan MD, Newton K, Hecht J, Russo JE, Spertus JA. Depression and health status in elderly patients with heart failure: a 6-month prospective study in primary care. Am J Geriatr Cardiol. 2004;13: 252-60.

5. Rumsfeld JS, Havranek E, Masoudi FA, et al. Depressive symptoms are the strongest predictors of short-term declines in health status in patients with heart failure. J Am Coll Cardiol. 2003;42:1811-7.

6. Jiang W, Alexander J, Christopher E, et al. Relationship of depression to increased risk of mortality and rehospitalization in patients with congestive heart failure. Arch Intern Med. 2001;161:1849-56.

7. Sullivan M, Simon G, Spertus J, Russo J. Depression-related costs in heart failure care. Arch Intern Med. 2002;162:1860-6.

8. McClain CS, Rosenfeld B, Breitbart W. Effect of spiritual well-being on end-of-life despair in terminally-ill cancer patients. Lancet. 2003; 361:1603-7.

9. Nelson CJ, Rosenfeld B, Breitbart W, Galietta M. Spirituality, religion, and depression in the terminally ill. Psychosomatics. 2002; 43:213-20.

10. Lunney JR, Lynn J, Foley DJ, Lipson S, Guralnik JM. Patterns of functional decline at the end of life. JAMA. 2003;289:2387-92.

11. Jones AM, O'Connell JE, Gray CS. Living and dying with congestive heart failure: addressing the needs of older congestive heart failure patients. Age Ageing. 2003;32:566-8.

12. Westlake C, Dracup K. Role of spirituality in adjustment of patients with advanced heart failure. Prog Cardiovasc Nurs. 2001;16:119-25.

13. Havranek EP, Spertus JA, Masoudi FA, Jones PG, Rumsfeld JS. Predictors of the onset of depressive symptoms in patients with heart failure. J Am Coll Cardiol. 2004;44:2333-8.

14. Muldoon M, King N. Spirituality, health care, and bioethics. J Relig Health. 1995;34:329-49.

15. Sulmasy DP. A biopsychosocial-spiritual model for the care of patients at the end of life. Gerontologist. 2002;42 Spec No 3:24-33.

16. Hauptman PJ, Havranek EP. Integrating palliative care into heart failure care. Arch Intern Med. 2005;165:374-8

17. Pantilat SZ, Steimle AT. Palliative care for patients with heart failure. JAMA. 2004;291:2476-82.

18. Stevenson LW. Selection and management of candidates for heart transplantation. Curr Opin Cardiol. 1996;11:166-73.

19. Yesavage JA. Geriatric depression scale. Psychopharmacol Bull. 1988;24:709-11.

20. Yesavage JA, Sheikh JI. Geriatric depression scale (GDS): recent evidence and development of a shorter version. Clin Gerontol. 1986;6: 165-73.

21. Whooley MA, Browner WS. for the Study of Osteoporotic Fractures Research Group. Association between depressive symptoms and mortality in older women. Arch Intern Med. 1998;158:2129-35.

22. Arthur A, Jagger C, Lindesay J, Graham C, Clarke M. Using an annual over-75 health check to screen for depression: validation of the short Geriatric Depression Scale (GDS15) within general practice. Int J Geriatr Psychiatry. 1999;14(6):431-9.

23. Peterman AH, Fitchett G, Brady MJ, Hernandez L, Cella D. Measuring spiritual well-being in people with cancer: the functional assessment of chronic illness therapy-spiritual well-being scale (FACIT-Sp). Ann Behav Med. 2002;24:49-58.

24. Bekelman DB, Sullivan M. Depression and anxiety in patients with chronic heart failure. In: Beattie J, Goodlin S, eds. Supportive Care of the Cardiac Patient. Oxford: Oxford University Press, In Press.

25. Green CP, Porter CB, Bresnahan DR, Spertus JA. Development and evaluation of the Kansas City Cardiomyopathy Questionnaire: a new health status measure for heart failure. J Am Coll Cardiol. 2000;35: 1245-55.

26. Spertus J, Peterson E, Conard MW, et al. Monitoring clinical changes in patients with heart failure: a comparison of methods. Am Heart J. 2005; 150:707-15.

27. Heidenreich PA, Spertus JA, Jones PG, et al. Health status identifies heart failure outpatients at risk for hospitalization or death. J Am Coll Cardiol. 2006;47:752-6. 
28. Mitchell PH, Powell L, Blumenthal J, et al. A short social support measure for patients recovering from myocardial infarction: the ENRICHD Social Support Inventory. J Cardiopulm Rehabil. 2003;23:398-403.

29. Berkman LF, Blumenthal J, Burg M, et al. Effects of treating depression and low perceived social support on clinical events after myocardial infarction: the Enhancing Recovery in Coronary Heart Disease Patients (ENRICHD) Randomized Trial. JAMA. 2003;289: 3106-16.

30. Chang VT, Hwang SS, Feuerman M, Kasimis BS, Thaler HT. The memorial symptom assessment scale short form (MSAS-SF). Cancer. 2000;89:1162-71.

31. Tranmer JE, Heyland D, Dudgeon D, Groll D, Squires-Graham M, Coulson K. Measuring the symptom experience of seriously ill cancer and noncancer hospitalized patients near the end of life with the memorial symptom assessment scale. J Pain Symptom Manage. 2003;25:420-9.

32. Brown RL, Leonard T, Saunders LA, Papasouliotis O. A two-item conjoint screen for alcohol and other drug problems. J Am Board Fam Pract. 2001;14:95-106.

33. Molloy DW, Standish TI. A guide to the standardized Mini-Mental State Examination. Int Psychogeriatr. 1997;9 (Suppl 1):87-94

34. Geriatric Depression Scale. Available at: http://www.stanford.edu/ -yesavage/GDS.html. Accessed October 10, 2006

35. U.S. Census Bureau, Current Population Survey, 2006 Annual Social and Economic Supplement. Available at: http://pubdb3.census.gov/ macro/032006/hhinc/new02_001.htm. Accessed October 10, 2006.

36. Beery TA, Baas LS, Fowler C, Allen G. Spirituality in persons with heart failure. J Holist Nurs. 2002;20:5-25.
37. Murray SA, Kendall M, Boyd K, Worth A, Benton TF. Exploring the spiritual needs of people dying of lung cancer or heart failure: a prospective qualitative interview study of patients and their carers. Palliat Med. 2004;18:39-45.

38. Speck P, Higginson I, Addington-Hall J. Spiritual needs in health care. BMJ. 2004;329:123-4.

39. Brady MJ, Peterman AH, Fitchett G, Mo M, Cella D. A case for including spirituality in quality of life measurement in oncology. Psychooncology. 1999;8:417-28.

40. Steinhauser KE, Voils CI, Clipp EC, Bosworth HB, Christakis NA, Tulsky JA. "Are you at peace?" One item to probe spiritual concerns at the end of life. Arch Intern Med. 2006;166:101-5.

41. Chochinov HM, Cann BJ. Interventions to enhance the spiritual aspects of dying. J Palliat Med. 2005;8(suppl 1):S103-15.

42. Levin JS. How religion influences morbidity and health: reflections on natural history, salutogenesis and host resistance. Soc Sci Med. 1996;43 (5):849-64.

43. Breitbart w. Spirituality and meaning in supportive care: spiritualityand meaning-centered group psychotherapy interventions in advanced cancer. Support Care Cancer. 2002;10:272-80.

44. Chochinov HM, Hack T, Hassard T, Kristjanson LJ, McClement S, Harlos M. Dignity therapy: a novel psychotherapeutic intervention for patients near the end of life. J Clin Oncol. 2005;23:5520-5.

45. Mendes de Leon CF, Czajkowski SM, Freedland KE, Bang H, Powell LH, Wu C, et al. The effect of a psychosocial intervention and quality of life after acute myocardial infarction: the Enhancing Recovery in Coronary Heart Disease (ENRICHD) clinical trial. J Cardiopulm Rehabil. 2006;26:9-13. 